\title{
The effect of a participative product design process on user
}

\author{
performance*
}

\author{
**P. Vink ${ }^{\mathrm{a}, \mathrm{b}}$, D.J. van Eijk ${ }^{\mathrm{b}}$
}

${ }^{a}$ TNO, P.O. Box 718, 2130AS Hoofddorp, The Netherlands

${ }^{b}$ Delft University of technology, Industrial design engineering, Landbergstraat 15, 2628CE Delft. The Netherlands

\begin{abstract}
The use of hand tools can lead to accidents, overexertion injuries and discomfort. So, there is certainly room for better-designed hand tools, especially hand tools that contribute to better performance. In the literature the benefits of a participative product design approach are clearly shown. However, the effect of this approach is hardly ever measured at the hand tool performance level.

The goal of this project was to study the effect of a participative product design process on indicators of health, performance and comfort.
\end{abstract}


Two sets of screwdrivers were tested. One set was developed by a participative product design approach and the control by a traditional approach.

The study indicates positive effects of the participative approach. Some indicators for health and safety (discomfort in the hand and blisters) were significantly better for the test set compared with the control set. The effect on productivity is clearly shown (16\% higher productivity) and the positive effects on comfort are also shown.

It is discussed that it is plausible that in the long run some of the effects found in this study would still be seen under real working conditions, but long-term effects on health and safety still need to be studied.

Keywords: Overexertion injuries; Participatory ergonomics; Screwdrivers; Effect study

*This paper is based on a presentation of Vink and Eijk at the ISSA International Symposium "Design process and human factors integration" 2006, March 1-3, Nice. The character of the presentation has been maintained in this paper.

** Corresponding author. Tel.: +31 23 5549590; fax: +31 235549305.

E-mail address: P.Vink@ arbeid.tno.nl. 


\section{Introduction}

The use of hand tools can lead to over exertion injuries (Aghazadeh and Mital, 1987). The estimated compensation costs in the USA are $13,364,439,906$ dollar for overexertion (Leamon and Wellman, 2006), indicating that there is certainly room for improvement. Several studies show that less discomfort is experienced by using appropriately designed hand tools (e.g. Dempsey et al., 2002). This is of importance as discomfort can lead to musculoskeletal problems on the long term (Vink, 2005). The relationship between hand tool design and musculoskeletal disorders is not new. In 1978 Tichauer (1978) already mentioned this relationship. Analyzing 35 handling accidents of workers in petrol and diesel workshops, Laflamme et al. (1991) found that it was common for workers to be injured when using hand tools. They either lost control of the tool or the machine twisted in their hand resulting in a blow that caused injury. Of course in injuries and accidents many factors play a role, like environment and emotions of the users (e.g. Bena et al., 2006). However, designing a hand tool that increases performance and health could contribute to the reduction in accidents and injuries. This study concerns the effects of a hand tool design process. Measuring the effect of a specific design on overexertion and injuries is very complicated. Therefore, in this study short term effects are measured under standardized conditions.

At the moment there is no universal agreed approach to design a hand tool that increases productivity and health, but the positive effects of a participatory design process have been demonstrated before. The European Foundation for the Improvement 
of Living and Working Conditions (1999) reports that direct participation in production organizations most often leads to quality improvements (90\% of the cases), to reduction of throughput times (60\% of the cases), and to reduction of costs (60\% of the cases). Other papers also show positive aspects of the approach (Haines et al., 2002; Hendrick, 2005). Although, recently also a paper has been published showing that the participatory ergonomics approach does not work for late adopters (Molen et al., 2005). The effect of a participatory approach is mostly evaluated at the level of the organization, the approach, participants or work station (Vink, 2005), but not often at the level of the interaction between product and end-user. The aim of this paper is to study the effects of a participatory approach on the design of the hand tool.

\section{Aim of this study}

A participatory approach is more time consuming and probably more costly (Haines et al., 2002). Different prototypes have to be made (Bobjer and Jansson, 1997), which is more costly. Furthermore, usability and user testing is a specific skill which demand experienced researchers. It is doubtful that these investments pay off and contribute to productivity, health and comfort improvement and by that on the long run in preventing injuries and overexertion.

The hypothesis of this study is that investments in a participatory design process have no effect on productivity, health and comfort. 


\section{Method}

To test this hypothesis a participatively designed product (a screwdriver set) was compared with another screwdriver set that is also well-known in the professional market, has a comparable price, and did not pay extra attention to participation in the design process.

\subsection{Material}

In this case, participatively designed means that an 11-step program (Bobjer and Jansson 1997) was followed. In this program it is essential that operators are intensively involved. The 11-step program may be summarized as follows:

After a preliminary specification is made by interviewing and observing users (step 1), a market analysis (step 2) is conducted. In step 3, background information is collected from papers, textbooks, and reports, followed by the design of a first prototype (step 4). Then professionals are exposed to the experimental prototypes (step 5) and improvements are defined in interviews based on research (step 6). Another user test (step 7) is undertaken by a wider selection of users in several countries. In step 8 , the final design recommendations are made, followed by product specification (step 9). In step 10 another user test is performed to prove that the tool works, and the product is launched. In step 11, more scientific tests are performed to gather data for further improvement of the product. 
The control set of screwdrivers did not follow this 11-step program. There are some important characteristics that differ between the test screwdriver and the control. For instance, the test screwdriver grip is made of a special material that immediately matches the temperature of the user's hand, and it has a high friction coefficient relative to other screwdrivers. The diameter is larger at the handle end to support forceful use, but in the area close to the metal it has a smaller diameter to enable precision tasks (see fig. 1). The test set is also color-coded. Every type of screwdriver in the set (Phillips-head, slotted-head, etc.) has a different color code on top of the handle. The idea is that during work the screwdriver is found earlier by this feature.

\subsection{Subjects}

Eight subjects used both new sets of screwdrivers (the test set and the control set) on a standardized task. Subjects were not familiar with either screwdriver set and were not informed about the background. The subjects (average age 20 years) were students in their last year of automotive maintenance study. Manually operated (nonpowered) screwdrivers are still often seen in this sector. All subjects had at least 3 years of experience working intensively with hand tools, including nonpowered screwdrivers.

\subsection{Procedure}

Health and discomfort, productivity, and end-user opinion were evaluated during 
and after a standardized task (see fig. 2) and compared within one subject. The standard task was screwing 24 screws into a wooden object. The screws were of different types and sizes (Phillips-head screws of $3.5 \mathrm{~mm}$ and $4.5 \mathrm{~mm}$ and slotted-head screws of 4.0 $\mathrm{mm}$ and $5.0 \mathrm{~mm})$ and had to be fastened into drilled holes $(2.5 \mathrm{~mm}$ diameter, $30 \mathrm{~mm}$ deep) in a wooden object. This object had exactly the same dimensions in all situations. Twelve screws had to be screwed in forward (screw horizontal) and twelve downward (screw vertical), all in front of the body at elbow height, while the subjects were seated in a prescribed way on a fixed seat. The screwdrivers were positioned in a box on a low table to the left of the subject. The subjects had to replace the screwdrivers in the box after using each screwdriver. Four subjects started with the set of four test screwdrivers

and used the control set of four screwdrivers later. The other four subjects began with the control set, followed by the test set.

As the subjects (and teachers of the school) mentioned that sometimes working with oil on the hands could introduce new hazards an additional test was done with four screws. Half a thimble of oil was spread over the hand of the eight subjects before this additional test and forces were measured as well as the experience.

When possible, all of the differences between both sets were tested with the t-test for paired comparison $(\mathrm{p}<0.05)$.

\subsection{Measurement of health and discomfort indicators}

For every subject the test started by experiencing the local perceived discomfort 
(LPD) scale. Subjects were asked to rate their postural discomfort in one of the regions (see fig. 3) shown on a diagram of the rear view of the arm, using a scale ranging from 1 (no discomfort) to 5 (extreme discomfort). This LPD scale was based on and modified after Corlett and Bishop (1976) and Borg (1982). First, the subjects learned the LPD scale. For every region they had to rate their experienced discomfort every 30 seconds by holding a $5 \mathrm{~kg}$ weight with arms horizontal anterior to the body until they were unable to hold the weight. After a rest period the test started, but before each test an LPD form was completed (pretest). The form was also completed four times during the test. The subjects were asked to fasten six screws as fast as possible, followed by completion of the LPD form and a break of 1 minute. The pretest value was subtracted from the other four measurement values and the result was taken as the LPD value. The same procedure was performed using the other screwdriver after a break of 45 minutes.

In addition to LPD, postures were recorded by making lateral photographs with a camera from a fixed location. After the test, the subjects' hands were evaluated for redness and blisters, and questions were asked about experienced friction, pressure points, and feelings of cramp.

Before all tests the moment was measured by a special device. Subjects had to put the screwdrivers into the device and were asked to exert maximum force on a placebo screw mounted on a force measurement device. The same measurement was repeated for the other set of screwdrivers and after the test for the screw driver with oil.

\subsection{Measuring productivity indicators}


Productivity was recorded by measuring the time it took to fasten the twenty-four screws. Quality was measured by counting the number of incompletely fastened screws or screws that were not screwed straight into the drilled hole.

\subsection{Users opinion}

After all experiments were done, the subjects completed a questionnaire on health, perceived productivity, quality, and the characteristics of the screwdriver sets.

\section{Results}

An overview of the differences between the two sets of screwdrivers is shown in Table 1.

\subsection{Indicators for health and discomfort}

The differences in discomfort appeared to be very small. The differences were shown by subtracting the first of the four LPD measurements from the last LPD measurement. The total score (the sum of all regions) was lower for the test screwdrivers in the hand, but not significant. Also, in the lower-arm region the differences were not significant. In the hand, the local experienced discomfort was significantly lower working with the test set. 
Inspection of the hands showed differences between both sets. After working with the control set, three subjects were found to have blisters that were not observed after working with the test set. Four additional subjects reported that they expected to have blisters after working with the control set.

All subjects had problems with the high level of friction during the test, both for the test as well as for the control set. Four subjects complained about pressure on the ball of the thumb while working with the control set, and two subjects complained about this pressure with both sets. Working with the control set, two subjects experienced feelings of cramp, whereas no one experienced this working with the test set. Also, two subjects experienced irritating friction with the control set, but no one experienced this with the test set.

The average maximum force with the test screwdrivers was $40 \%$ higher than the force that was measured with the control screwdriver. This could be caused by the fact that the diameter averaged over the four grips was 1.18 times larger with the test screwdriver compared to the control. However, if we correct for this difference in diameter (momentarm) the average maximum force is still $34 \%$ higher.

Working with oil resulted in equal forces, but the 4 of the eight subjects had a preference for the control screwdrivers set.

\subsection{Indicators for productivity}

The average screw time was significantly lower with the test set than with the control set. The reduction in screwing time was $16 \%$, and the number of errors was also 
lower. Working with the control set resulted in thirty-three sloping screws or partly fixed screws, whereas using the test set resulted in only six of these errors.

\subsection{End user opinion}

The users' preferences are presented in Table 2. Most of the users prefer the test set in regard to faster work, force exertion, balance, and grip on the handle and screw. The experienced comfort rating is better for the test set, as well as the average score. After this research, one subject chose the control. His motivation was that the brand of the control hand tool is used often in his sector.

\section{Discussion}

If we assume that the parameters of this study are good indicators for health, productivity, and comfort, the hypothesis that attention for a participative design process has no effect on health, productivity, and comfort in using a hand tool is falsified, which indicates a lower risk of injuries and overexertion. In this section the effects on health, productivity, and comfort are discussed per subject, followed by general remarks.

\subsection{Indicator for health}

The indicators for health are local experienced discomfort and blisters. Previous studies (Grinten et al., 1991) demonstrated that the variables constructed provide reliable 
results for comparison of conditions, such as in this study. Furthermore, for groups of subjects, reasonably linear relationships were found between load in the body and discomfort in a body region (Boussena et al. 1982), as well as between discomfort and holding time (Manenica, 1986). Also, increased heart rates are observed with high discomfort values (Bystrom, 1991). In a longitudinal study among 1700 employees (Vink, 2005) it was shown that a higher discomfort increased the chance of musculoskeletal injuries. This strengthens our assumption that LPD is related to health. The LPD in the hand is lower with the test set, which could therefore be more healthful to use. The combination of pressure and local friction, which stretches the skin three to seven millimeters and also chafes the skin (Hall, 1995), is hazardous for the skin because it could result in blisters. The test set probably has lower values for pressure, friction, and chafing, which reduces the chance of blisters. The force level needed to insert the screw is lower with the test set, partly because of the diameter of the handle, partly because of a better fit in the hand, and partly because of the material used to make the screwdriver. This is in alignment with the fact that the chance of blisters is lower with the test set.

However, some care should be taken regarding the conclusion that the test set is more healthful. First, for both screwdriver sets the experienced friction is high; second, a reduction in discomfort is shown in the hand region, but there is no significant reduction seen in total discomfort. Also, the test situation was tougher than actual working situations in order to increase the chance of showing differences. It could take a long time for these differences to be found in a real work environment, also in part because pneumatic or electric tools could be used for some screwdriving tasks. Furthermore, only some short-term health effects (discomfort in the hand and blisters) are studied in this 
experiment, although long-term effects should be studied as well. Regarding hazards it was mentioned by the subjects that working with oil increases the hazards. The test set was not better regarding this aspect. There is certainly room for improvement in this area.

Generalizing the results should also be done with care, because only eight young male subjects accustomed to screwdriving were studied. The effects on older persons or persons not used to screwdriving could be larger. Nevertheless, objective as well as subjective data indicate all trend in the same direction, which allows a conclusion that this study indicates that the test set is better from a health point of view.

\subsection{Indicators of productivity}

Objective as well as subjective data indicate a productivity increase with the test set. In other words, the time needed to complete a specific screwing task is reduced significantly using the test set. Also, the users found that the test set works faster. Not only is the task performed faster, but also the quality is better (fewer errors), which means that less repair time is required afterwards. It is to be expected that under real working conditions this productivity increase of $16 \%$ would also be found. The effect of that value will probably be lower because the intensive screwdriving performed in the test will rarely be found during real work, but in reality errors should be repaired quickly as well.

\subsection{Comfort}


According to Kuijt et al. (2005) comfort is mostly determined by functionality and physical infraction using hand tools. Adverse body effects like cramped muscles, causes blisters, cause inflamed skin, underlie both comfort and discomfort (Kuijt-Evers et al. 2005). Discomfort and comfort are very subjective, and the best way to measure discomfort is therefore by questioning. In this study likewise results are shown. There is more discomfort in the hand tool that has more blisters and needs more force. Parameters influencing comfort positively—such as faster work, lower force exertion, and a better grip on the handle and screw_-are evaluated positively as well. Based on these data, it could be assumed that all subjects would buy the test set, after the test one subject still favors the control set. This shows how many factors influence a person's preference.

\subsection{Drawbacks of this test}

As discussed earlier, extrapolation of these results to real working situations is difficult, because the test conditions were extreme and the subjects were a select group. However, standardizing the test conditions and increasing the loading on the human body was needed in order to ensure that differences were found. It is plausible that in the long run some of the effects found in this study would still be seen under real working conditions, but long-term effects on health and safety still need to be studied.

Of course this study could not demonstrate that the specific eleven-step participative design program mentioned caused the better performance of the test set. The important parts of the development process cannot be shown either. Therefore, this study only indicates that finding some way to emphasize ergonomics and the participation of end users is important to improve indicators for health, productivity, and comfort of 
workers using the end product and thereby reduce the chance of injuries and overexertion. Ergonomics is important because this discipline focuses on adapting products to the behavior of humans using them. User participation is needed in product development because users are the only ones who can evaluate comfort during normal use of a product. To anticipate on that user participation is the only possibility.

\section{Conclusions}

Investments in ergonomics and user participation in product design (a participative product design process) can result in more healthful, productive, and comfortable products. In this chapter the effects can be shown objectively using an ergonomically and participatively designed screwdriver in a specific test situation, with specific subjects. However, health and comfort are very difficult to study objectively. In this study, only the effects on specific aspects of health (discomfort in the hand and blisters) could be shown. Long-term health effects should be studied further. The effect on productivity is clearly shown, indicating that a participative design process can increase performance. The effects on several aspects influencing increase in comfort are also shown, but the comfort aspects studied are not strong enough to convince all the subjects to buy the participative designed product. 


\section{References}

Aghazadeh, F., Mital, A., 1987. Injuries due to hand tools; results of a questionnaire. Applied Ergonomics 18, 273-278.

Bena, A., Mamo, C., Marinacci, C., Pasqualini, O., Tomaino, A., Campo, G. Costa. G. 2006. Risk of repeat accidents by economic activity in Italy. Safety Science 44, $297-$ 312.

Bobjer, O., Jansson, C., 1997. A research approach to the design of ergonomic hand tools. The 11-point programme. In: Seppälä, P., Luopajärvi, T., Nygård, C.H., Mattila, M. (Eds.), From Experience to Innovation. Proceedings of the 13th Triennial Congress of the International Ergonomics Association, Vol. 2 (Helsinki, June 29-July 4 1997), Finnish Institute of Occupational Health, Helsinki, pp.193-195.

Borg, G., 1982. Psychophysical bases of perceived exertion. Medicine and Science in Sports and Exercise 14, 377-381.

Boussena M., Corlett, E.N., Pheasant, S.T., 1982. The relation between discomfort and postural loading at the joints. Ergonomics 25, 315-322.

Byström, S., 1991. Physiological Response and Acceptability of Isometric Handgrip Contractions. Arbetsmiljöinstitutet (Arbete och Hälsa), Solna.

Corlett, E.N., Bishop, R.N., 1976. A technique for assessing postural discomfort. Ergonomics 19, 175-182.

Dempsey, P.G., McGorry, R.W., O’Brien, N.V., 2004. The effect of work height, workpiece orientation, gender, and screwdriver type on productivity and wrist deviation. International Journal of Industrial Ergonomics 33: 339-346. 
European Foundation for the Improvement of Living and Working Conditions, 1999. Communiqué July/August, 1999, Dublin: EFILWC, 2.

Grinten, M.P. van der, 1991. Test-retest reliability of a practical method for measuring body part discomfort. In Kumar, S. (Ed.), Advances in Industrial Ergonomics and Safety IV, pp 311-318.

Haines, H., Wilson, J.R., Vink, P. and Koningsveld, E.A.P., 2002. Validating a framework for participatory ergonomics. Ergonomics, 45, 309-327.

Hall, C., 1995. Hand Function with Special Regard to Work with Tools. NIOH (Arbete Och Hälsa 4), Stockholm.

Hendrick, H., 2005. ODAM and macroergonomics 20 years later: you've come a long way baby. In: Carayon, P., Robertson, M., Kleiner, B., Hoonakker ,P.L.T. (Eds.), Human Factors in Organizational Design and Management - VIII. Proceedings of the Eighth International Symposium on Human Factors in Organizational Design and Management held in Maui, Hawaii, USA, June 22-25, 2005. IEA Press, Santa Monica, pp. 443-448

Kuijt-Evers L.F.M., Twist, J. Groenesteijn, L. Looze, M.P. de, Vink, P., 2005. Identifying predictors of comfort and discomfort in using hand tools using the comfort questionnaire for hand tools (CQH), Ergonomics 48, 692 - 702.

Laflamme, L., Döös, M., Backström, T., 1991. Identifying accident patterns using the FAC and HAC: their application to accidents at the engine workshops of an automobile and truck factory. Safety Science 14, 13-33.

Leamon, T., Wellman, H., 2006. The contribution of ergonomics to the reduction of the 
burden of occupational injury. Presentation at the Symposium ISSA, Nice.

Manenica, I., 1986. A technique for postural load assessment.In: Corlett, E.N., Mananica, I., Wilson, J.R. (Eds.), The Ergonomics of Working Postures, Taylor \& Francis, London, pp 270-277.

Molen, H.F. van der, Sluiter, J.K., Hulshof, C.T.J., Vink, P., Duivenbooden, C. van, Holman, R., Frings-Dresen, M.H.W., 2005. Implementation of participatory ergonomics intervention in construction companies. Scandinavian Journal of Work Environment and Health 31, 191-203.

Tichauer, 1978. The Biomechanical Basis of Ergonomics. John Wiley \& Sons, New York.

Vink, P., 2005. Comfort and design: principles and good practice. CRC Press, Baco Raton. 
Figures
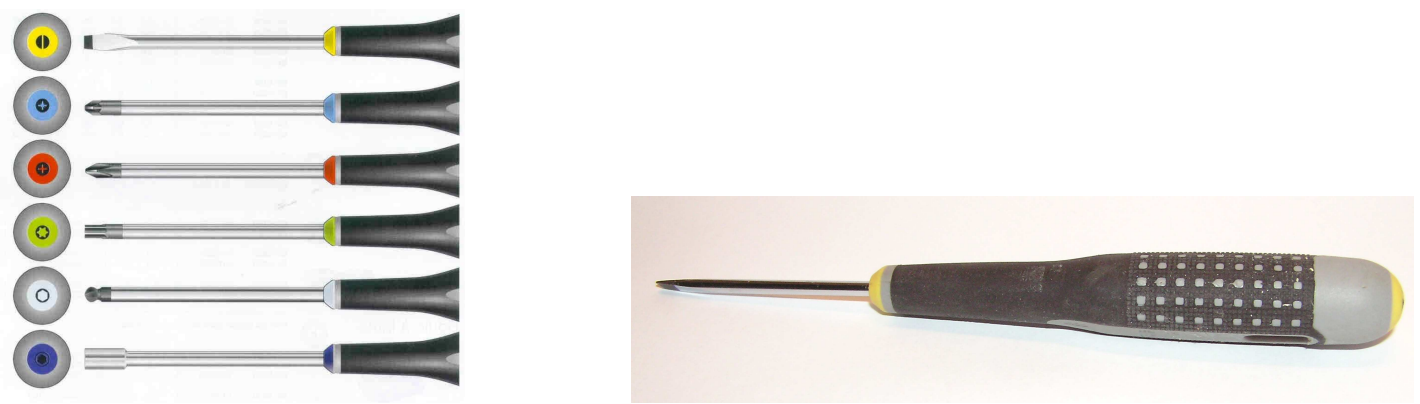

Figure $1 \mathrm{a}($ left $)$ and $1 \mathrm{~b}$ (right). One of the set participatively and ergonomically designed screwdrivers (1a). In the area close to the metal it has a smaller diameter to enable precision tasks with a pinch grip (1b).

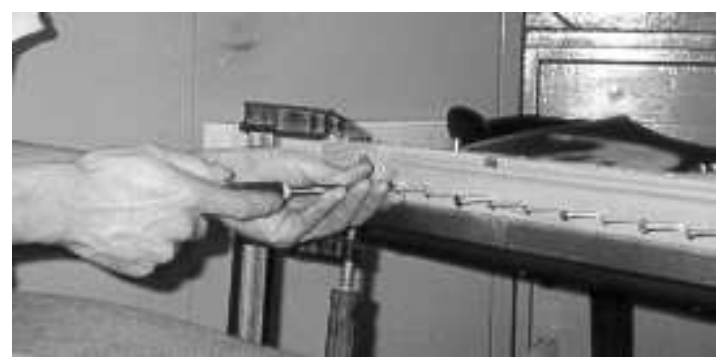

Figure 2. A drawing of the situation during the test.

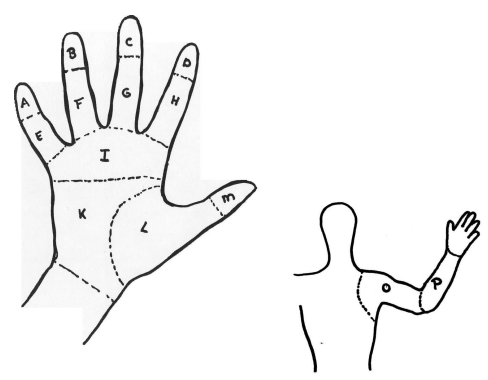

Figure 3. The drawing used to evaluate local postural discomfort. Four times during the test the subjects had to report their discomfort in the different regions A through $\mathrm{P}$, using a scale from 0 to $5(0=$ no problems at all; $1=$ very little discomfort; $2=$ some discomfort; 3 = much discomfort; 4 = a lot of discomfort; $5=$ maximal discomfort). 
Table 1

Overview of the differences between both screwdrivers

Local Postural Discomfort in \% of the

Test set

Control

maximal difference between the last

measurement and pretest, averaged over 8

subjects

- total

$55 \%(\mathrm{sd}=23)$

$61 \%(\mathrm{sd}=25)$

- hand

$30 \%(\mathrm{sd}=16)^{*}$

$45 \%(\mathrm{sd}=21)$

- lower arm

$31 \%(\mathrm{sd}=22)$

$18 \%(\mathrm{sd}=22)$

productivity

- average duration of the task (seconds)

- number of wrong screws

$829(\mathrm{sd}=88)^{*}$

6

$140 \%(\mathrm{sd}=11) *$

reference

eference

(averaged over 8 subjects)

experience of users:

- experienced comfort

- yes, I would choose this screwdriver

- average score (1= worse, $10=$ superb)

$\begin{array}{cc}8 \text { yes* } & 0 \text { yes } \\ 7 \text { yes* } & 1 \text { yes } \\ 7,6(\mathrm{sd}=1,0)^{*} & 6,3(\mathrm{sd}=1,2)\end{array}$

*significant difference ( $t$-test for paired comparison, $p<0,05$ )

Table 2

Preferences given after the test by the 8 subjects, regarding the topics described in the left column

Preference for

- faster working

- force exertion

- good grip on handle

- good grip on the screw

- good grip with oil on the grip

- balance

I would buy this set
Test set

6

6

7

5

4

8

6

No Control
difference

20

20

$1 \quad 0$

30

$1 \quad 3$

$0 \quad 0$


